\title{
Análises das produções científicas sobre cuidados de enfermagem a pessoas com úlcera venosa: revisão integrativa
}

\author{
Analysis of scientific productions on nursing care for people with venous \\ ulcer: integrative review
}

\author{
Anne Kayline Soares Teixeira' • Lúcia de Fátima da Silva² • Antonia Natielli Costa da Silva ${ }^{3}$ \\ Emanoel David Alves Freire ${ }^{4}$. Hellen Kelle Lima de Menezes ${ }^{5}$ Maria Sinara Farias $^{6}$ \\ Luana Maria Bráz Benevides ${ }^{7}$ Gabriela Costa e Silva ${ }^{8}$
}

\begin{abstract}
RESUMO
Objetivo: Objetivou-se analisar criticamente as produções científicas acerca do cuidado de enfermagem ao paciente com úlcera venosa. Método: Trata-se de um estudo exploratório, descritivo, com abordagem qualitativa, inclui a análise crítica de estudos relevantes, adotando método sistemático e rigoroso de busca em bases de dados confiáveis, possibilitando conhecimento de determinados assuntos para a prática clínica de enfermagem segura e baseada em evidência. Resultados: A priori, 188 publicações foram identificadas. A posteriori, aplicaram-se três Testes de Relevância (TR). TR I, considerando os critérios de inclusão e exclusão, TR II, que consistia na leitura do título e do resumo do artigo e TR III, que consistiu na leitura na íntegra identificando sua pertinência. Discussão: Observase com a revisão realizada que, os enfermeiros vêm publicando estratégias de cuidados baseados em métodos curativos e tecnológicos a pacientes com úlcera venosa. Conclusões: Este estudo possibilitou observar a produção de conhecimento científico por enfermeiros sobre cuidados com úlcera venosa, bem como a elaboração e utilização de ferramentas no atendimento, dandoauxilio nas condutas. $O$ estudo demonstra as principais atividades do enfermeiro aos pacientes com lesões venosas, utilizando abordagens alternativas e estratégias para adesão do paciente à terapêutica, tornando-a cada vez mais eficiente.

Palavras-chave: Cuidados de Enfermagem; Úlcera Varicosa; Doenças Vasculares; Insuficiência Venosa.
\end{abstract}

\begin{abstract}
Objective: The objective was to critically analyze the scientific productions about nursing care to the patient with venous ulcer. Method:This is an exploratory study, descriptive study with a qualitative approach, includes the critical analysis of relevant studies, adopting a systematic and rigorous method of searching reliable databases, making possible the knowledge of certain subjects for clinical practice of safe and evidence-based nursing. Results: Initially, I88 publications were identified. Subsequently, three Relevance Tests (TR) were applied. TR I, considering the inclusion and exclusion criteria, TR II, which consisted of reading the title and the abstract of the article and TR III, which consisted of reading in full, identifying its relevance. Discussion: It's observed with the review that nurses have been publishing strategies of care based on curative and technological methods for patients with CVI and active venous ulcer. Conclusion: This study made it possible to observe the production of scientific knowledge by nurses about venous ulcer care, as well as the elaboration and use of tools in the care, giving assistance in the ducts. The study demonstrates the main activities of nurses to patients with venous ulcer care, using alternative approaches and strategies for patient adherence to therapy, making it increasingly efficient.
\end{abstract}

Keywords: Nursing Care;Varicose Ulcer;Vascular Diseases;VenousInsufficiency. 


\section{INTRODUÇÃO}

As úlceras venosas são lesões crônicas de pele, que compreendem a principal manifestação clínica da insuficiência venosa crônica. Nela, ocorre a incapacidade do sistema valvar e/ou obstrução venosa, decorrente de varizes primárias, trombose venosa profunda ou outras causas que alteram o retorno venoso, como anomalias valvulares. Em consequência, há hipertensão do sistema venoso dos membros inferiores, com estiramento dos capilares e extravasamento de macromoléculas para a derme, formando uma barreira física para o transporte de nutrientes, resultando nas ulcerações ${ }^{(1)}$.

As úlceras venosas geralmente acometem membros inferiores, em região de maléolo e localizada sobre o vaso insuficiente (quando espontâneas) ou decorrente de traumas. Apresentam-se com formato irregular, superficiais inicialmente, porém com grande potencial para tornar-se profundas, podendo ter presença de exsudatos típicos da granulação ou de uma infecção subjacente. A pele adjacente pode ser lipodermatoesclerose, hiperpigmentada, descamativa, ressecada, eritematosa e/ou edemaciada, compreendendo também os sinais clínicos presentes no membro com insuficiência venosa, somado a veias varicosas, telangiectasia, veias reticulares, dor, prurido, eczema de estase(2).

Os fatores de risco para o aparecimento desta lesão são: idade avançada, a obesidade, ferimentos anteriores nas pernas, trombose venosa profunda e flebite. Normalmente as úlceras são irregulares, superficiais e localizadas sobre proeminências ósseas, é comum tecidos de granulação e fibrina estarem presentes na base da úlcera. $O$ mau prognóstico compreende em úlcera de grande tamanho e em uma longa duração na cicatrização(3).

Estima-se que no Brasil a prevalência e a incidência de úlcera venosa seja de 0,10 a $0,30 \%$ e de 3 a 5 casos $/ 1000$ por ano, respectivamente. Tais números representam em sua maioria pessoas idosas, residentes em instituições de longa permanência, sob internação hospitalar e portadoras de diabetes mellitus, evidenciando gravidade quando associada a doenças crônicas não transmissíveis. No entanto, este problema em idosos ainda é pouco explorada pelos estudiosos. Devido a sua cronicidade, constituem um alarmante problema de saúde pública, causando impactos físicos, psicossociais, socioeconômicos, além de altos custos no tratamento, que é duradouro e complexo, levando a hospitalização prolongada(4).

Do ponto de vista diagnóstico, o clínico ganha destaque, com a anamnese, afim de identificar fatores desencadeantes, tais como: histórico de traumatismos nos membros inferiores, queixa de varizes, história pregressa de trombose venosa profunda e edemas. A dor é frequente com intensidade variável, que em geral está presente no fim do dia e melhora com a elevação dos membros; e o exame físico para constatar as manifestações presentes no leito da ferida e da pele periferida, já mencionadas anteriormente, além da realização do índice tornozelo braquial (ITB), para confirmar o diagnóstico diferencial das outras úlceras crônicas, tais como as de etiologia arterial. Após o estabelecer o diagnóstico clínico, é necessária a realização de exames, como o Doppler, pletismografia e o duplex scan, para corroborar o resultado e identificar precisamente as alterações anatômicas e funcionais do sistema venoso, seja profundo, superficial ou em conjunto. Além de verificar se a causa da insuficiência venosa é refluxo, obstrução ou ambos ${ }^{(5)}$.

A escolha do tratamento adequado depende de um diagnóstico clínico e laboratorial correto, e do reconhecimento das complicações, tais como as infecções, dermatites e osteomielites, afim de tratá-las. O foco é a cicatrização da lesão, e a redução das recidivas, para isso contamos com diversas opções de tratamento; a terapia compressiva elástica (meias e bandagens), inelástica (Bota de unna) e pneumática intermitente, com o objetivo de reduzir a hipertensão, agindo na microcirculação, aumentando o retorno venoso e diminuindo o refluxo durante a deambulação; a terapia local, compreendendo a limpeza e antissepsia da úlcera, além da avaliação da necessidade de desbridamento e da quantidade e característica do exsudato presente, afim de escolher um curativo adequado; medicamentoso (por exemplo pentoxifilina, aspirina, diosmin), apesar de não muito bem elucidado, parecem estimular a cicatrização; e o tratamento cirúrgico da anormalidade venosa, como a cirurgia das veias varicosas, visando a cicatrização da úlcera ${ }^{(6)}$.

O cuidado de enfermagem com as úlceras venosas devem estar presentes desde o diagnóstico até após a cicatrização da lesão e consequente alta, compreendendo a observação dos sinais clínicos, das complicações, a escolha dos curativos com base nos custos e na clínica do paciente objetivando a cicatrização adequada, a realização de ações que visem reduzir os fatores de risco, prevenir futuras complicações e recidivas, por meio da orientação do paciente, e da promoção da saúde para uma melhoria na qualidade de vida do portador de úlcera venosa. Para isso contamos com o processo de enfermagem, escalas para avaliação da cicatrização e da qualidade de vida, além de diversas outras tecnologias de tratamento, como os coberturas interativas $^{(7)}$.

Considerando os aspectos abordados, o profissional enfermeiro necessita estar preparado para desenvolver o cuidado holístico ao paciente portador de úlcera venosa, além de contribuir para melhoria nas opções terapêuticas. Nesse sentido, elaborou-se a pergunta norteadora: "O que os enfermeiros têm publicado na literatura nacional e internacional sobre cuidados a pessoas com úlceras venosas?" Assim objetivou-se analisar as produções científicas acerca do cuidado de enfermagem ao paciente com úlcera venosa.

\section{MÉTODO}

Estudo exploratório, descritivo, com abordagem qualitativa. Optou-se como referencial a revisão integrativa de literatura. Este método de pesquisa inclui a análise crítica de estudos relevantes, adotando método sistemático e rigoroso de busca em bases de dados confiáveis, possibilitando conhecimento de determinados assuntos para a prática clínica de enfermagem segura e baseada em evidência ${ }^{(8)}$.

Para elaboração do estudo foram utilizadas as seguintes etapas: elaboração da questão norteadora, busca na literatura, produção dos dados, análise crítica dos artigos incluídos, comparação das evidências e apresentação da revisão(8).

Para melhor direcionamento, foi elaborada a seguinte questão norteadora: $O$ que os enfermeiros têm publicado na literatura nacional e internacional sobre cuidados a pessoas com úlceras venosas?

A figura 01 evidencia os passos da execução do estudo de revisão integrativa metodológica.

Foi estabelecido como critério de inclusão: manuscritos disponíveis na íntegra, com recorte temporal de cinco anos, na língua portuguesa, inglesa ou castelhano, que abordem o cuidado de enfermagem a pessoa com úlcera venosa. Sendo 
o cuidado de enfermagem, alguma intervenção do profissional enfermeiro voltado a esta clientela a fim de melhorar sua condição de saúde.

Excluíram-se: resumos, anais, editoriais, cartas ao editor, revisões bibliográficas, estudo de reflexão, duplicidade, artigos com detalhamento incompleto, estudos que envolvem apenas caracterização de pacientes, dissertações, teses, artigos sem enfermeiro como autor, artigos como objeto de estudo os enfermeiros.

Figura 0 I - Passos para revisão integrativa. Fortaleza-CearáBrasil, 2018.

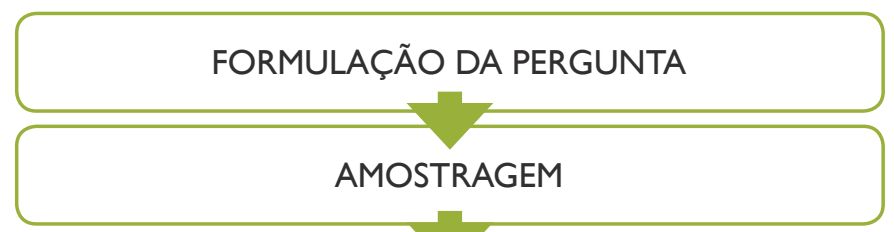

\section{EXTRAÇÃO DE DADOS DOS ESTUDOS PRIMÁRIOS}

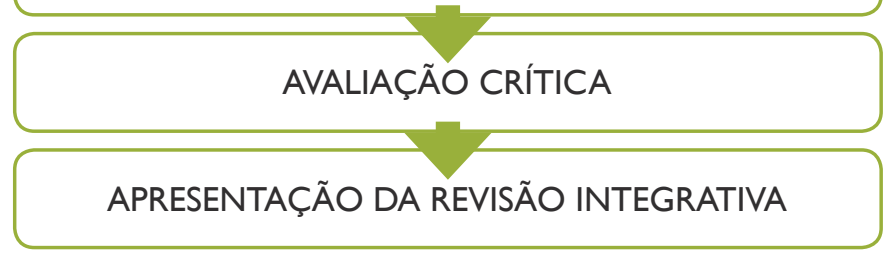

Fonte: Elaborado pela autora, 2018

A busca ocorreu nos meses de março e abril de 2018, utilizando-se os descritores controlados na seguinte equação de busca: úlcera varicosa OR úlcera venosa AND enfermagem.

Para a seleção dos artigos foram utilizadas as seguintes bases de dados: BDENF - Base de dados em Enfermagem, LILACS Literatura Latino-Americana e do Caribe em Ciências de Saúde, IBECS - Indice Bibliográfico Español de Ciencias de laSalud (via Biblioteca Virtual em Saúde - BVS), PUBMED - National Library of Medicine and National Institutes of Health (via Portal CAPES), biblioteca eletrônica Scielo-Br (ScientificElectronic Library Online) e MEDLINE - Medical LiteratureAnalysisandRetrieval
System Online.

Para seleção e apresentação dos estudos foi utilizado o instrumento Preferred Reportingltems for Systematic Review and Meta-Analyses(PRISMA) ${ }^{(9,10)}$.

Os estudos selecionados foram categorizados com base em um instrumento adaptado de URSI (2006), utilizado código na caracterização dos estudos, objetivo, intervenção e desfecho.

Para a classificação do nível de evidência (NE), foi adotado o proposto por Melnyk e Fineout-Overholt ${ }^{(11)}$ : nível I evidências procedentes de revisão sistemática ou metanálise de ensaios clínicos randomizados controlados relevantes ou originados de diretrizes clínicas baseadas em revisões sistemáticas de ensaios clínicos randomizados controlados; nível 2 - evidências obtidas de, pelo menos, um ensaio clínico randomizado controlado bem delineado; nível 3 - evidências obtidas de ensaios clínicos bem delineados sem randomização; nível 4 - evidências oriundas de estudos de coorte e de casocontrole bem delineados; nível 5 - evidências originárias de revisão sistemática de estudos descritivos e qualitativos; nível 6 - evidências procedentes de um único estudo descritivo ou qualitativo; nível 7 - evidências procedentes de opinião de autoridades e/ou relatório de comitês de especialistas.

\section{RESULTADOS}

A priori, 188 publicações foram identificadas. A posteriori, aplicaram-se três Testes de Relevância (TR).

A seleção preliminar das referências foi realizada por meio do TR I, considerando os critérios de inclusão e exclusão, sendo incluídas 96 publicações no primeiro momento. Posteriormente foi aplicado o TR II, que consistia na leitura do título e do resumo do artigo, em seguida aos artigos selecionados, procedeu-se o TR III, que consistiu na leitura na íntegra identificando sua pertinência.

A seguir mostra-se o fluxograma da seleção das publicações para a revisão integrativa, baseado no modelo PRISMA (Figura 02).

Foram selecionados 33 estudos, categorizados com base em um instrumento, utilizando código na identificação, objetivo, resultado e conclusão.

Figura 02 - Fluxograma da seleção das publicações para a revisão integrativa, baseado no modelo PRISMA. Fortaleza-CearáBrasil, 2018.
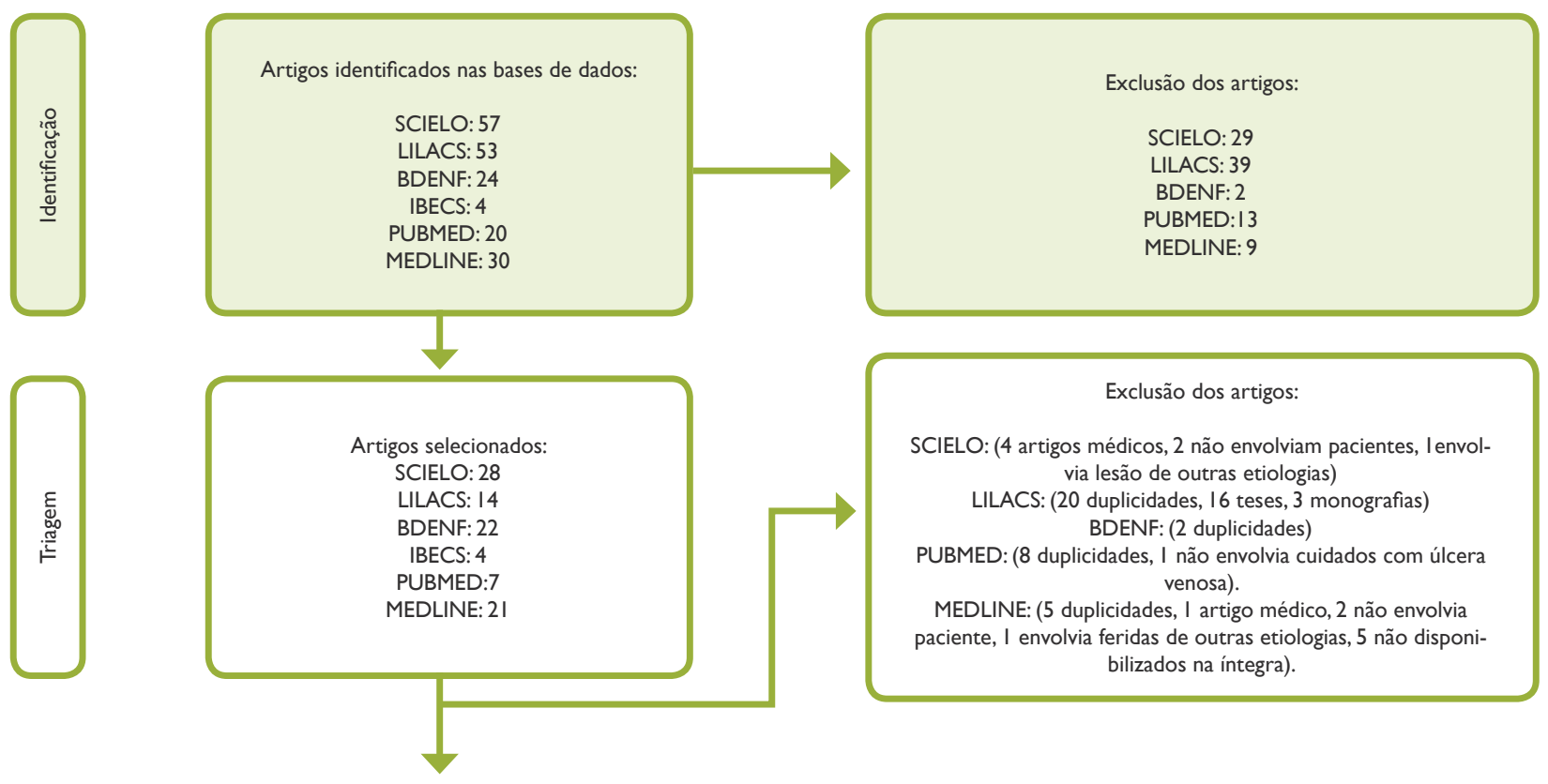


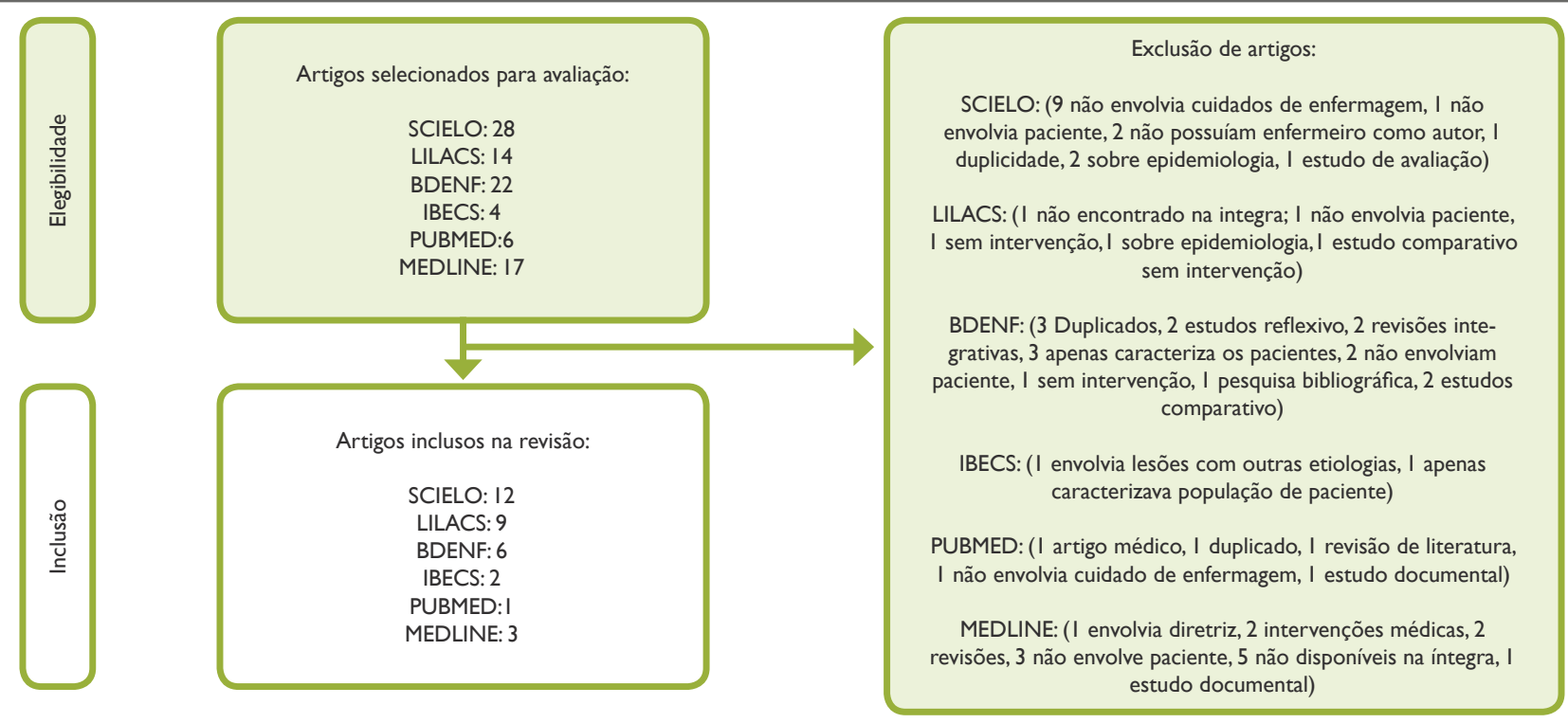

Dos artigos selecionados, 26 foram publicados em língua portuguesa, 5 na língua inglesa e 2 em espanhol.

Sobre as bases de dados, 12 artigos foram publicados no

No que se refere ao nível de evidência (NE) (tabela I), a grande maioria dos estudos são NE $6(n=17)$, seguido por $N E$ $2(n=6)$. SCIELO, 9 na LILACS, 6 na BDENF, 2 na IBECS, I na PUBMED e 3 na MEDLINE.

Figura 02 - Fluxograma da seleção das publicações para a revisão integrativa, baseado no modelo PRISMA. Fortaleza-CearáBrasil, 2018.

\begin{tabular}{|c|l|c|c|}
\hline Nível de evidência & \multicolumn{1}{|c|}{ Tipo de Estudo } & N & $\%$ \\
\hline Nível I & $\begin{array}{l}\text { Revisão sistemática metanálise de ensaios clínicos randomizados contro- } \\
\text { lados relevantes diretrizes clínicas baseadas em revisões sistemáticas de } \\
\text { ensaios clínicos randomizados controlados }\end{array}$ & 2 & $6 \%$ \\
\hline Nível 2 & Um ensaio clínico randomizado controlado & 6 & $18 \%$ \\
\hline Nível 3 & Ensaios clínicos bem delineados sem randomização & 1 & $3 \%$ \\
\hline Nível 4 & Estudos de coorte e de caso-controle & 5 & $15 \%$ \\
\hline Nível 5 & Revisão sistemática de estudos descritivos e qualitativos & 0 & $0 \%$ \\
\hline Nível 6 & Estudo descritivo ou qualitativo & 17 & $52 \%$ \\
\hline Nível 7 & Opinião de autoridades e/ou relatório de comitês de especialistas & 2 & $6 \%$ \\
\hline \multicolumn{1}{|c|}{ TOTAL } & $\mathbf{3 3}$ & $\mathbf{1 0 0 \%}$ \\
\hline
\end{tabular}

Fonte: Dados obtidos nas bases de dados selecionadas, 2018

A tabela 02 a seguir revela a caracterização dos estudos no que diz respeito às intervenções de enfermagem.

Tabela 02 - Caracterização dos estudos com base no tipo de intervenção, cuidados de enfermagem ao público-alvo. Fortaleza, CE, Brasil. 2018.

\begin{tabular}{|c|c|c|}
\hline Cuidado/intervenção de enfermagem & $\mathbf{N}$ & $\%$ \\
\hline $\begin{array}{l}\text { Terapias adjuvantes: uso de terapias compressivas, bota de Unna, bandagens, coberturas interativas, oxigenoterapia hiperbárica, } \\
\text { uso de plantas medicinais. }\end{array}$ & 14 & $41 \%$ \\
\hline Estudos fenomenológicos e compreensão & 7 & $22 \%$ \\
\hline Intervenções metodológicas: protocolos, sistemas, softweres, cartilhas, escalas. & 7 & $22 \%$ \\
\hline Diagnósticos, uso do processo de enfermagem e elaboração de consulta de enfermagem. & 3 & $9 \%$ \\
\hline Programas de aconselhamento e educação e Visita domiciliar. & 2 & $6 \%$ \\
\hline TOTAL & 33 & $100 \%$ \\
\hline
\end{tabular}

Fonte: Dados obtidos nas bases de dados selecionadas, 2018

O quadro 0 I traz o resumo dos estudos identificados na revisão integrativa. Caracterizou-se em: código do estudo, objetivo, intervenção e desfecho. 
Quadro 0I - Distribuição e caracterização dos estudos incluídos na revisão integrativa com base estudo, objetivo, intervenção e desfecho. Fortaleza-Ceará-Brasil, 2018

\begin{tabular}{|c|c|c|c|}
\hline Código & Objetivo & Intervenção & Desfecho \\
\hline $\mathrm{Al}$ & $\begin{array}{l}\text { Validação clínica de um protocolo } \\
\text { assistencial. }\end{array}$ & $\begin{array}{l}\text { Os especialistas sugeriram modi- } \\
\text { ficações nas categorias: anamnese; } \\
\text { exames; verificação da dor e pulsos; } \\
\text { tratamento cirúrgico da doença } \\
\text { venosa crônica; prevenção de recidi- } \\
\text { va; referência e contrarreferência. }\end{array}$ & $\begin{array}{l}\text { O protocolo foi validado no } \\
\text { contexto clínico, e sua composição, } \\
\text { após os ajustes, foi de } 15 \text { categorias } \\
\text { e } 76 \text { itens. A validação otimizou o } \\
\text { instrumento quanto à aplicabilidade } \\
\text { e à pertinência. }\end{array}$ \\
\hline $\mathrm{A} 2$ & $\begin{array}{l}\text { Compreender através de um estudo } \\
\text { fenomenológico o cotidiano do } \\
\text { homem que convive com a úlcera. }\end{array}$ & $\begin{array}{l}\text { As categorias identificadas revelam } \\
\text { que a convivência do homem com a } \\
\text { ferida produz repercussões no âmb- } \\
\text { ito produtivo e na sexualidade. Isso } \\
\text { o leva a restrições na vida cotidiana, } \\
\text { com prejuízo no desempenho de } \\
\text { papéis socialmente estabelecidos } \\
\text { para o gênero masculino, o que } \\
\text { desperta no homem a ansiedade pela } \\
\text { retomada das atividades. }\end{array}$ & $\begin{array}{l}\text { Os achados sinalizam aspectos viven- } \\
\text { ciais relevantes que podem orientar } \\
\text { os profissionais no planejamento e } \\
\text { execução de ações de saúde voltadas } \\
\text { para essa clientela. }\end{array}$ \\
\hline $\mathrm{A} 3$ & $\begin{array}{l}\text { Apresentar um sistema especial- } \\
\text { ista denominado PROTUV- soft- } \\
\text { ware(protocolo para Tratamento de } \\
\text { úlcera) para apoiar o processo de } \\
\text { decisão dos enfermeiros na terapia } \\
\text { tópica das úlceras venosas. }\end{array}$ & $\begin{array}{l}\text { Sistemas especialistas constituem } \\
\text { uma classe de sistemas da Inteligên- } \\
\text { cia Artificial que executam funções } \\
\text { semelhantes àquelas normalmente } \\
\text { executadas por um especialista } \\
\text { humano. }\end{array}$ & $\begin{array}{l}\text { A utilização de recursos viabi- } \\
\text { liza a educação permanente dos } \\
\text { enfermeiros sobre o tratamento de } \\
\text { feridas, bem como a inclusão digital } \\
\text { destes enfermeiros para o uso deste } \\
\text { sistema. }\end{array}$ \\
\hline A4 & $\begin{array}{l}\text { Comparar a mensuração de área de } \\
\text { úlcera venosa por meio dos soft- } \\
\text { wares Auto } C A D \& \text { e Image Tool. }\end{array}$ & $\begin{array}{l}\text { Os tamanhos das úlceras apre- } \\
\text { sentaram grande amplitude, porém, } \\
\text { sem diferença significativa entre as } \\
\text { mensurações, existe excelente cor- } \\
\text { relação intraclasse e de concordân- } \\
\text { cia entre os softwares. }\end{array}$ & $\begin{array}{l}\text { O uso de ambos os softwares é } \\
\text { indicado para a mensuração de UV, } \\
\text { parecendo ser mais precisos quando } \\
\text { utilizados para mensurar feridas com } \\
\text { área }>10 \mathrm{~cm}^{2} \text {. }\end{array}$ \\
\hline A5 & $\begin{array}{l}\text { Analisar o processo de reparo tecid- } \\
\text { ual de pacientes com UV em uso da } \\
\text { terapia compressiva inelástica (Bota } \\
\text { de Unna), em comparação ao uso da } \\
\text { bandagem elástica. }\end{array}$ & $\begin{array}{l}\text { Ocorreu redução significativa, no } \\
\text { nível de } 5 \% \text {, na área, em centímetros } \\
\text { quadrados, das úlceras do grupo } \\
B(p<0,000 \text { I) ao longo de todo o } \\
\text { tratamento, e tendência do grupo } \\
\text { A redução, na área da úlcera, em } \\
\text { centímetros quadrados ( } \mathrm{p}=0,06) \text {, } \\
\text { apenas após a quinta semana. }\end{array}$ & $\begin{array}{l}\text { A Bota de Unna apresentou melhor } \\
\text { resultado em UV com áreas superi- } \\
\text { ores a } 10 \mathrm{~cm}^{2} \text { e redução significativa } \\
\text { do exsudato. }\end{array}$ \\
\hline A6 & $\begin{array}{l}\text { Avaliar o efeito clínico de tratamen- } \\
\text { to tópico com mel de Ulmo asso- } \\
\text { ciado à administração oral de ácido } \\
\text { ascórbico em pacientes portadores } \\
\text { de UV. }\end{array}$ & $\begin{array}{l}\text { Terapia combinada.A aplicação tópi- } \\
\text { ca diária de mel de Ulmo foi realiza- } \\
\text { da de acordo com a norma técnica } \\
\text { de tratamento avançado combinada } \\
\text { com o consumo diário de } 500 \mathrm{mg} \\
\text { de ácido ascórbico. Cicatrização } \\
\text { completa foi observada em } 100 \% \text { das } \\
\text { úlceras venosas. }\end{array}$ & $\begin{array}{l}\text { Tratamento proposto apresentou } \\
\text { resultados clínicos excelentes na } \\
\text { cicatrização das UV.Além de favore- } \\
\text { cer o desbridamento, o mel não é } \\
\text { aderente, é fácil de aplicar e remover, } \\
\text { e é de fácil aceitação por parte dos } \\
\text { usuários. }\end{array}$ \\
\hline A7 & $\begin{array}{l}\text { Avaliar a dor em pacientes porta- } \\
\text { dores de UV de membros inferiores } \\
\text { que utilizaram curativo de espuma } \\
\text { não aderente com lbuprofeno. }\end{array}$ & $\begin{array}{l}\text { Grupo intervenção e grupo e } \\
\text { controle. Aplicação do questionário } \\
\text { de Dor de McGill. Os pacientes do } \\
\text { Grupo Controle manifestaram todas } \\
\text { as sensações de dor da escala desses } \\
\text { até quinta a consulta. }\end{array}$ & $\begin{array}{l}\text { O curativo de espuma não aderente } \\
\text { com lbuprofeno é eficaz na redução } \\
\text { da dor de pacientes portadores de } \\
\text { UV. }\end{array}$ \\
\hline A8 & $\begin{array}{l}\text { Avaliar a eficácia de curativos com } \\
\text { membrana de Celulose Bacteriana } \\
\text { (CB) no tratamento de UV de mem- } \\
\text { bros inferiores. }\end{array}$ & $\begin{array}{l}\text { Houve uma redução na área de feri- } \\
\text { da em ambos os grupos. Não houve } \\
\text { infecção ou reações ao produto em } \\
\text { nenhum dos grupos. Pacientes do } \\
\text { grupo CB mostraram diminuição da } \\
\text { dor e interrupção mais precoce do } \\
\text { uso de analgésicos. }\end{array}$ & $\begin{array}{l}\text { A membrana de CB pode ser usada } \\
\text { como curativo para o tratamento } \\
\text { de úlceras varicosas dos membros } \\
\text { inferiores. }\end{array}$ \\
\hline A9 & $\begin{array}{l}\text { Construir e validar uma tecnologia } \\
\text { educativa (cartilha) para cuidados } \\
\text { com UV. }\end{array}$ & $\begin{array}{l}\text { Cartilha para cuidados com úlcera } \\
\text { venosa, constituída de sete tópicos: } \\
\text { Alimentação, Caminhadas e ex- } \\
\text { ercícios leves, Repouso com a perna } \\
\text { elevada, Cuidados com o curativo, } \\
\text { Terapia compressiva, Apoio familiar, } \\
\text { e manter hábitos saudáveis. Teste } \\
\text { piloto revelou que I00\% das pessoas } \\
\text { com UV avaliaram o texto como } \\
\text { compreensivo e as ilustrações, como } \\
\text { adequadas. }\end{array}$ & $\begin{array}{l}\text { A tecnologia educativa mostrou-se } \\
\text { valida quanto à aparência e ao con- } \\
\text { teúdo, com potencial de utilização na } \\
\text { prática clínica. }\end{array}$ \\
\hline
\end{tabular}




\begin{tabular}{|c|c|c|c|}
\hline AlO & $\begin{array}{l}\text { Analisar a efetividade dos géis de pa- } \\
\text { paína a } 2 \% \text { e } 4 \% \text { no reparo tecidual } \\
\text { das UV. }\end{array}$ & $\begin{array}{l}\text { Houve redução média de } 7,9 \mathrm{~cm} 2 \\
\text { (50\% do tamanho) em } 90 \text { dias; } \\
20 \% \text { cicatrizaram completamente } \\
\text { em } 56,67 \text { dias. Houve aumento da } \\
\text { epitelização, redução significativa do } \\
\text { esfacelo e do edema, melhora na } \\
\text { profundidade, no tipo e na quanti- } \\
\text { dade de exsudato ( } p<0,000 \mathrm{l} \text { ). }\end{array}$ & $\begin{array}{l}\text { Os géis de papaína a } 2 \% \text { e } 4 \% \text { foram } \\
\text { efetivos na cicatrização de UV. }\end{array}$ \\
\hline All & $\begin{array}{l}\text { Avaliar o impacto da visita domiciliar } \\
\text { na capacidade funcional de pacientes } \\
\text { adultos e idosos com UV antes e } \\
\text { após as orientações recebidas em } \\
\text { domicilio. }\end{array}$ & $\begin{array}{l}\text { Os participantes do grupo caso } \\
\text { apresentaram melhora significativa e } \\
\text { diferenciada pós-intervenção quando } \\
\text { comparados aos do grupo controle, } \\
\text { que se mantiveram estáveis. }\end{array}$ & $\begin{array}{l}\text { As orientações no contexto domicil- } \\
\text { iar foram benéficas aos integrantes } \\
\text { do grupo caso. }\end{array}$ \\
\hline $\mathrm{A} / 2$ & $\begin{array}{l}\text { Compreender através de um estudo } \\
\text { fenomenológico a vivência de cuida- } \\
\text { do de pessoas com UV em uso da } \\
\text { Bota de Unna. }\end{array}$ & $\begin{array}{l}\text { Foram desveladas as categorias:"O } \\
\text { incomodo da bota de Unna versus } \\
\text { a melhora da ferida","Dificuldades } \\
\text { para o acesso ao cuidado com a } \\
\text { Bota de Unna","Cuidar para cica- } \\
\text { trizar e prevenir recidivas" e "Rece- } \\
\text { ber mais atenção do profissional de } \\
\text { saúde". }\end{array}$ & $\begin{array}{l}\text { A vivência de cuidado de pessoas } \\
\text { em uso da Bota de Unna revelou o } \\
\text { incomodo proporcionado por este } \\
\text { dispositivo, superado pela melhora } \\
\text { da ferida. As questões do universo } \\
\text { intersubjetivo dessas pessoas devem } \\
\text { ser consideradas na gestão do } \\
\text { cuidado da UV. }\end{array}$ \\
\hline $\mathrm{A} / 3$ & $\begin{array}{l}\text { Avaliar a efetividade do gel de } \\
\text { papaína a } 2 \% \text { comparado ao gel de } \\
\text { carboximetilcelulose a } 2 \% \text { no trata- } \\
\text { mento de pacientes com UV. }\end{array}$ & $\begin{array}{l}\text { O grupo experimento apresentou } \\
\text { redução significativa da área das } \\
\text { lesões, especialmente no período } \\
\text { entre a } 5^{\mathrm{a}} \text { e a } 12^{\mathrm{a}} \text { semana de trata- } \\
\text { mento, com duas úlceras cicatrizadas } \\
\text { e aumento expressivo da quantidade } \\
\text { de tecido de epitelização no leito } \\
\text { das lesões. }\end{array}$ & $\begin{array}{l}\text { O gel de papaína a } 2 \% \text { apresentou } \\
\text { maior efetividade quanto à redução } \\
\text { da área das lesões, entretanto, se } \\
\text { mostrou similar ao gel de carboxi- } \\
\text { metilcelulose a } 2 \% \text {, quanto à redução } \\
\text { da quantidade de exsudato e de } \\
\text { tecido desvitalizado. }\end{array}$ \\
\hline $\mathrm{A} \mid 4$ & $\begin{array}{l}\text { Analisar a eficiência da tecnologia } \\
\text { Bota de Unna no processo de cica- } \\
\text { trização de úlceras varicosas. }\end{array}$ & 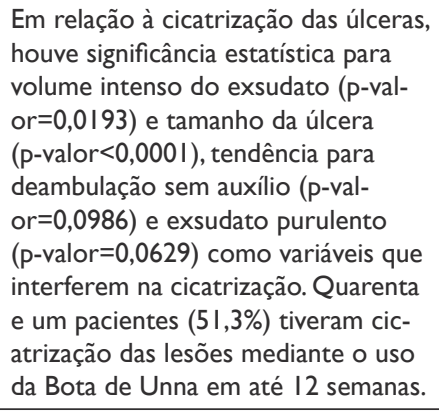 & $\begin{array}{l}\text { A tecnologia foi eficiente na cica- } \\
\text { trização das úlceras varicosas, em } \\
\text { especial nas úlceras de pequeno } \\
\text { tamanho. }\end{array}$ \\
\hline AI5 & $\begin{array}{l}\text { Analisar os diagnósticos de enfer- } \\
\text { magem em pessoas com UV. }\end{array}$ & $\begin{array}{l}\text { Identificaram-se I6 diagnósticos, } \\
\text { sendo que } 100 \% \text { dos participantes } \\
\text { apresentaram: Integridade tissu- } \\
\text { lar prejudicada, Perfusão tissular } \\
\text { periférica ineficaz, Risco de infecção, } \\
\text { Mobilidade física prejudicada e } \\
\text { Autocontrole ineficaz da saúde. } \\
\text { Estes diagnósticos encontram-se } \\
\text { nos domínios Segurança/Proteção, } \\
\text { Atividade/Repouso e Promoção da } \\
\text { Saúde. }\end{array}$ & $\begin{array}{l}\text { Do ponto de vista da prática clínica } \\
\text { devem ser focos prioritários na } \\
\text { intervenção e avaliação de enfer- } \\
\text { magem. }\end{array}$ \\
\hline Al6 & $\begin{array}{l}\text { Identificar as experiências con- } \\
\text { struídas pelas pessoas com UV, no } \\
\text { processo de conviver com esta } \\
\text { condição crônica. }\end{array}$ & $\begin{array}{l}\text { As três categorias submetidas à } \\
\text { análise foram: Úlcera venosa e a sua } \\
\text { repercussão no trabalho; Mudanças } \\
\text { na rotina e limitações no viver com } \\
\text { a úlcera venosa; e conviver com a } \\
\text { úlcera venosa e a necessidade de } \\
\text { cuidado profissional e familiar. }\end{array}$ & $\begin{array}{l}\text { A pessoa com úlcera venosa pode } \\
\text { apresentar propensão a desenvolver } \\
\text { problemas que colocam em risco a } \\
\text { sua saúde física e emocional e que } \\
\text { necessita de atenção integral dos } \\
\text { profissionais da saúde. }\end{array}$ \\
\hline Al7 & $\begin{array}{l}\text { Conhecer as alterações ocorridas } \\
\text { no cotidiano de pessoas acometidas } \\
\text { pela UV. }\end{array}$ & $\begin{array}{l}\text { Mostraram que as úlceras varicosas } \\
\text { e suas constantes recidivas reper- } \\
\text { cutem diretamente no cotidiano dos } \\
\text { indivíduos acometidos, uma vez que, } \\
\text { limitam muitas das suas atividades de } \\
\text { vida diária bem como provocam o } \\
\text { isolamento social. }\end{array}$ & $\begin{array}{l}\text { Identificaram-se limitações nas ativ- } \\
\text { idades cotidianas de lazer e laborais, } \\
\text { aposentadoria por invalidez, bem } \\
\text { como sentimentos e sensações de } \\
\text { angústia e sofrimento que interferem } \\
\text { em suas relações sociais. }\end{array}$ \\
\hline
\end{tabular}




\begin{tabular}{|c|c|c|c|}
\hline Al8 & $\begin{array}{l}\text { Descrever a evolução da cicatrização } \\
\text { e o trata } \text {-mento realizado em } \\
\text { pacientes com úlceras de perna no } \\
\text { ambulatório de feridas, utilizando o } \\
\text { instrumento PressureUlcerScale for } \\
\text { Healing - PUSH }\end{array}$ & $\begin{array}{l}\text { A aplicação da Escala PressureUlcer- } \\
\text { Scale for Healing na avaliação dos } 4 \\
\text { pacientes deste estudo possibilitou } \\
\text { aos enfermeiros realizar a prescrição } \\
\text { da cobertura ideal para o processo } \\
\text { cicatricial da lesão. }\end{array}$ & $\begin{array}{l}\text { O referido instrumento facilita } \\
\text { sobremaneira a atuação da enfer- } \\
\text { magem na avaliação e na escolha da } \\
\text { cobertura ideal para a promoção } \\
\text { da epitelização da lesão, uma vez } \\
\text { que tem por base a avaliação de } \\
\text { parâmetros importantes durante } \\
\text { o processo dinâmico do cuidar de } \\
\text { feridas. }\end{array}$ \\
\hline $\mathrm{A} 19$ & $\begin{array}{l}\text { Avaliar bem-estar subjetivo e de- } \\
\text { pressão em pessoas idosas com UV. }\end{array}$ & $\begin{array}{l}\text { Foram identificados } 23(4 I, 82 \%) \\
\text { idosos com UV nível da depressão } \\
\text { leve ou moderada, e } 26(47,28 \%) \\
\text { depressão severa. Relacionado à } \\
\text { Escala Bem-estar Subjetivo a maioria } \\
\text { dos participantes do estudo apre- } \\
\text { sentaram alteração nos domínios: } \\
43(78,20 \%) \text {, satisfação com a vida, e } \\
40(72,70 \%) \text {. }\end{array}$ & $\begin{array}{l}\text { Os indivíduos apre } \text { sentam de- } \\
\text { pressão entre leve a severa e queda } \\
\text { na qualidade de vida. Sentem } 7 \text {-se } \\
\text { infelizes, e insatisfeitos com a vida. }\end{array}$ \\
\hline A20 & $\begin{array}{l}\text { Avaliar o processo de cicatrização } \\
\text { de paciente com UV em membro } \\
\text { inferior submetido ao tratamento } \\
\text { com Bota de Unna. }\end{array}$ & $\begin{array}{l}\text { Utilizou-se para a avaliação do } \\
\text { processo de cicatrização da úlcera o } \\
\text { protocolo com dados clínicos, men- } \\
\text { suração da área da lesão e o registro } \\
\text { fotográfico. Após doze semanas de } \\
\text { acompanhamento, a úlcera apre- } \\
\text { sentou-se cicatrizada e o paciente } \\
\text { relatou melhora da dor e diminuição } \\
\text { do edema nas pernas. }\end{array}$ & $\begin{array}{l}\text { O tratamento com a Bota de Unna } \\
\text { mostrou-se efetivo na cicatrização } \\
\text { da úlcera venosa quando aliado a } \\
\text { um acompanhamento ambulatorial } \\
\text { sistematizado. }\end{array}$ \\
\hline$A 21$ & $\begin{array}{l}\text { Descrever a evolução da cicatrização } \\
\text { de úlcera crônica de perna, utilizan- } \\
\text { do o instrumento PressureUlcer- } \\
\text { Scale for Healing(PUSH). }\end{array}$ & $\begin{array}{l}\text { Aos } 9 \text { meses de tratamento, } 19 \\
(38 \%) \text { pacientes apresentavam úlcera } \\
\text { fechada; I } 7 \text { (34\%), úlceras com teci- } \\
\text { do de granulação; e I } 4 \text { (28\%), tecido } \\
\text { epitelizado. }\end{array}$ & $\begin{array}{l}\text { O instrumento PUSH possibili- } \\
\text { tou acompanhar o processo de } \\
\text { cicatrização da lesão por meio da } \\
\text { avaliação de comprimento versus } \\
\text { largura, quantidade do exsudato e } \\
\text { tipo de tecido existente na ferida, } \\
\text { favorecendo, assim, a escolha da } \\
\text { cobertura ideal para cada fase da } \\
\text { cicatrização. }\end{array}$ \\
\hline A22 & $\begin{array}{l}\text { Avaliar a eficácia do uso da bota de } \\
\text { Unna artesanal no tratamento de UV } \\
\text { e acompanhar o desenvolvimento da } \\
\text { cicatrização das feridas. }\end{array}$ & $\begin{array}{l}\text { Observando-se as diferenças nos } \\
\text { tempos de cicatrização das feridas, } \\
\text { em relação aos três momentos de } \\
\text { avaliação, evidenciou-se que após a } \\
\text { avaliação inicial houve diminuição } \\
\text { da área da ferida, semelhante tanto } \\
\text { para o grupo I como para o grupo } \\
2 \text { ( }>0,05) \text {. }\end{array}$ & $\begin{array}{l}\text { A utilização da Bota de Unna arte- } \\
\text { sanal contribui para aceleração no } \\
\text { processo cicatricial. }\end{array}$ \\
\hline A23 & $\begin{array}{l}\text { Descrever os saberes e práticas } \\
\text { de pessoas com úlcera venosa em } \\
\text { tratamento com bota de Unna. }\end{array}$ & $\begin{array}{l}\text { Os saberes se relacionam à causa } \\
\text { circulatória e as práticas, com o } \\
\text { repouso e a cicatrização da úlcera } \\
\text { venosa. A bota de Unna foi citada } \\
\text { como tratamento benéfico e facili- } \\
\text { tador, embora possa proporcionar } \\
\text { algum incômodo. }\end{array}$ & $\begin{array}{l}\text { Referiram conhecimento sobre a } \\
\text { origem da lesão, realizavam práticas } \\
\text { de cuidado para melhora no retorno } \\
\text { venoso e a bota de Unna foi consid- } \\
\text { erada um tratamento benéfico. }\end{array}$ \\
\hline A24 & $\begin{array}{l}\text { Descrever o cuidado em saúde } \\
\text { realizado pelas pessoas com UV em } \\
\text { assistência ambulatorial. }\end{array}$ & $\begin{array}{l}\text { Da análise elaboraram-se as catego- } \\
\text { rias: Cuidados com a alimentação - } \\
\text { "alimentação como fonte de saúde"; } \\
\text { Ferida como centro do cuidado } \\
\text { - "tudo em função da perna" e } \\
\text { repouso como cuidado- "dizem que } \\
\text { o repouso é o principal". }\end{array}$ & $\begin{array}{l}\text { As práticas de cuidado realizadas } \\
\text { pelas pessoas com úlcera venosa } \\
\text { referem-se à alimentação, à ferida e } \\
\text { ao repouso. Essas devem ser con- } \\
\text { hecidas pela enfermagem, pois isso } \\
\text { possibilitará a troca e aproximação } \\
\text { de saberes em busca de um cuidado } \\
\text { congruente. }\end{array}$ \\
\hline A 25 & $\begin{array}{l}\text { Conhecer a utilização de plantas } \\
\text { medicinais por pessoas com UV } \\
\text { acompanhadas no ambulatório de } \\
\text { um hospital público. }\end{array}$ & $\begin{array}{l}\text { Elaboraram-se as categorias: Plantas } \\
\text { medicinais utilizadas no cuidado da } \\
\text { úlcera venosa;Aprendizado no cuida- } \\
\text { do com plantas medicinais; e Formas } \\
\text { de uso das plantas medicinais no } \\
\text { cuidado à úlcera venosa. }\end{array}$ & $\begin{array}{l}\text { As plantas são utilizadas na forma } \\
\text { de chá ou diretamente na lesão. } \\
\text { Esse cuidado antecede a busca aos } \\
\text { serviços de saúde ou ocorre de } \\
\text { forma complementar as práticas } \\
\text { profissionais. Faz-se importante a } \\
\text { enfermagem identificar a influência } \\
\text { desse conhecimento popular no cui- } \\
\text { dado a pessoas com úlcera venosa. }\end{array}$ \\
\hline
\end{tabular}




\begin{tabular}{|c|c|c|c|}
\hline A26 & $\begin{array}{l}\text { Investigar o sentimento de inclusão } \\
\text { social de pessoas com UV. }\end{array}$ & $\begin{array}{l}\text { Pessoas com UV percebem a lesão } \\
\text { como um sofrimento, preferem } \\
\text { atividades de lazer do tipo exclusivas } \\
\text { como assistir à televisão, algumas } \\
\text { se sentem incluídas na sociedade } \\
\text { e outras sofrem com o estigma de } \\
\text { ter a lesão, afastadas do convívio de } \\
\text { familiares. }\end{array}$ & $\begin{array}{l}\text { Faz-se necessário repensar práticas } \\
\text { assistenciais inclusivas e receptivas } \\
\text { que transcendam a técnica de cura- } \\
\text { tivo e compreendam o ser humano } \\
\text { em sua complexidade. }\end{array}$ \\
\hline A27 & $\begin{array}{l}\text { Identificar aspectos validados por } \\
\text { juízes para elaboração de protocolo } \\
\text { de assistência a pessoas com UV. }\end{array}$ & $\begin{array}{l}\text { Aspectos de composição do proto- } \\
\text { colo: avaliação do paciente e lesão, } \\
\text { registro/documentação, cuidado com } \\
\text { ferida/pele perilesional, indicação } \\
\text { de cobertura, uso de antibiótico } \\
\text { e tratamento da dor, tratamento } \\
\text { cirúrgico/medicamentoso, melhoria } \\
\text { do retorno venoso e prevenção } \\
\text { de recidiva, encaminhamento dos } \\
\text { pacientes, capacitação, referência/ } \\
\text { contra-referência. }\end{array}$ & $\begin{array}{l}\text { Para compor o protocolo, fazem-se } \\
\text { necessários aspectos referentes a } \\
\text { diagnóstico, tratamento e prevenção } \\
\text { das lesões. }\end{array}$ \\
\hline A28 & $\begin{array}{l}\text { Identificar o grau de comprometi- } \\
\text { mento da integridade tissular de pa- } \\
\text { cientes com úlcera venosa de acordo } \\
\text { com a classificação dos resultados de } \\
\text { enfermagem. }\end{array}$ & $\begin{array}{l}\text { Cinco indicadores apresentaram } \\
\text { comprometimento moderado } \\
\text { (mediana=3): dor, perfusão tissular, } \\
\text { pigmentação anormal, crescimento } \\
\text { cutâneo de pelos e tecido cicatricial. }\end{array}$ & $\begin{array}{l}\text { A maioria dos indicadores avaliados } \\
\text { nos pacientes entrevistados apre- } \\
\text { sentou grau de comprometimento } \\
\text { variando de leve a moderado. }\end{array}$ \\
\hline A29 & $\begin{array}{l}\text { Descrever os tipos mais frequentes } \\
\text { de feridas com indicação para } \\
\text { terapia por oxigênio hiperbárica e os } \\
\text { resultados obtidos. }\end{array}$ & $\begin{array}{l}\text { As feridas mais frequentemente } \\
\text { encontradas como indicação para } \\
\text { terapia por oxigênio hiperbárico } \\
\text { foram: úlcera venosa, lesão traumáti- } \\
\text { ca e pé diabético. Os pacientes } \\
\text { com feridas crônicas realizaram um } \\
\text { menor número de sessões }(61,1 \%) \text { e } \\
\text { tiveram suas feridas cicatrizadas ou } \\
\text { reduzidas }(62,0 \%) \text { quando compara- } \\
\text { dos com aqueles com feridas agudas. }\end{array}$ & $\begin{array}{l}\text { A terapia por oxigênio hiperbárico } \\
\text { é um tratamento efetivo para pa- } \\
\text { cientes com feridas crônicas. }\end{array}$ \\
\hline $\mathrm{A} 30$ & $\begin{array}{l}\text { Avaliar os benefícios e danos das } \\
\text { intervenções destinadas a ajudar as } \\
\text { pessoas a aderir à terapia de com- } \\
\text { pressão da UV e, assim, melhorar a } \\
\text { cicatrização das UV e prevenir a sua } \\
\text { recorrência após a cicatrização. }\end{array}$ & $\begin{array}{l}\text { Evidência de baixa qualidade de um } \\
\text { ensaio clínico ( } 67 \text { participantes) } \\
\text { indica que, em comparação com os } \\
\text { cuidados domiciliares, um Leg Club® } \\
\text { baseado na comunidade resultou } \\
\text { em uma redução estatisticamente } \\
\text { significativa na dor aos seis meses. }\end{array}$ & $\begin{array}{l}\text { No momento não é possível } \\
\text { recomendar ou desencorajar as } \\
\text { intervenções de cuidados clínicos da } \\
\text { enfermeira em relação aos cuidados } \\
\text { padrão. Há uma escassez de ensaios } \\
\text { de intervenções que promovem a } \\
\text { adesão à terapia de compressão } \\
\text { para UV. }\end{array}$ \\
\hline$A 31$ & $\begin{array}{l}\text { Descrever a evolução do tratamen- } \\
\text { to da UV com o uso de cobertura } \\
\text { avançada (alginato de cálcio) e } \\
\text { apresentar as respostas do paciente } \\
\text { à frente dos cuidados prestados na } \\
\text { atenção primária à saúde. }\end{array}$ & $\begin{array}{l}\text { Resposta rápida com diminuição da } \\
\text { dor e cura e melhoria dos impactos } \\
\text { negativos com uso de cobertura } \\
\text { adequada como alginato de cálcio, } \\
\text { cuidado sistemático e profissional } \\
\text { capacitado. }\end{array}$ & $\begin{array}{l}\text { O tratamento foi possível devido } \\
\text { à disponibilidade de cobertura } \\
\text { adequada e ao conhecimento dos } \\
\text { profissionais para conduzir o caso. }\end{array}$ \\
\hline A32 & $\begin{array}{l}\text { Desenvolver um modelo simples de } \\
\text { consulta baseada em evidências, com } \\
\text { pacientes e profissionais, com foco } \\
\text { na qualidade de vida. }\end{array}$ & $\begin{array}{l}\text { Um modelo A4 frente e verso de } \\
\text { fácil utilização foi projetado para } \\
\text { concentrar as consultas enfer- } \\
\text { meiro-paciente nos desafios de } \\
\text { qualidade de vida apresentados pelas } \\
\text { UV crônicas da perna. }\end{array}$ & $\begin{array}{l}\text { Este novo modelo ajudará a garantir } \\
\text { que as principais preocupações } \\
\text { sejam efetivamente levantadas, ex- } \\
\text { ploradas e abordadas durante cada } \\
\text { consulta. }\end{array}$ \\
\hline A33 & $\begin{array}{l}\text { Avaliar o conhecimento dos } \\
\text { pacientes sobre a doença venosa } \\
\text { crônica, ocorrência da UV e } \\
\text { recorrência, e auto-cuidado no } \\
\text { início, imediatamente e após, } 2 \text { e } \\
9 \text { semanas após uma intervenção } \\
\text { educativa realizada no domicilio } \\
\text { dos sujeitos. }\end{array}$ & $\begin{array}{l}\text { Projeto de educação para } \\
\text { melhorar o conhecimento de } \\
\text { autogestão da estase venosa.A } \\
\text { intervenção educacional resultou } \\
\text { em um aumento estatistica- } \\
\text { mente significativo nos escores } \\
\text { de conhecimento ( } P=0,002) \text {. } \\
\text { Esta mudança persistiu quando } \\
\text { os pacientes foram avaliados } \\
\text { durante } 2 \text { e } 9 \text { semanas de acom- } \\
\text { panhamento ( }(\mathrm{P}=0,003) \text {. Além } \\
\text { disso, metade dos pacientes } \\
\text { que completaram a intervenção } \\
\text { educacional permaneceu livre de } \\
\text { recorrência quando avaliada em } \\
9 \text { semanas. }\end{array}$ & $\begin{array}{l}\text { Os resultados sugerem que a } \\
\text { educação do paciente relaciona- } \\
\text { da às úlceras venosas melhora o } \\
\text { conhecimento sobre o processo } \\
\text { da doença e o autocuidado e } \\
\text { reduz a recorrência quando } \\
\text { medida às } 9 \text { semanas após a } \\
\text { intervenção. }\end{array}$ \\
\hline
\end{tabular}




\section{DISCUSSÃo}

Observa-se com a revisão realizada que, os enfermeiros vêm publicando tanto na literatura nacional, como em literatura internacional, estratégias de cuidados baseados em métodos curativos e tecnológicos a pacientes com IVC e úlcera venosa ativa.

Para melhor entendimento optou-se em dividir a discussão em cinco categorias.

\section{Estudos envolvendo uso de terapias adjuvantes para o cuidado}

Nesta categoria foram analisados 15 estudos, ou seja, $45 \%$ em sua totalidade.

Estudos que abrangem questões referentes ao uso de terapias compressivas elásticas e inelásticas, como as botas de Unna foram relatados em seis artigos ${ }^{(12-14)}$.Sabe-se que terapia compressiva é padrão ouro no tratamento da UV, sem adesão do paciente, fica difícil a cicatrização, bem como evitar as recidivas das lesões.

Segundo a maioria dos estudos encontrados, com o uso da bota de Unna nota-se melhor resultado relacionado à redução no tamanho das lesões e redução de exsudato. Porém, há uma escassez de ensaios de intervenções que promovem a adesão à terapia de compressão(23).

Ainda sobre a temática, oito artigos trazem terapias tópicas como terapia adjuvante para cicatrização das lesões venosas $^{(15-18)}$. Estudo revela que, o tratamento com mel tópico e vitamina $C$, mostram resultados clínicos excelentes na cicatrização das úlceras venosas. $O$ mel além de favorecer o desbridamento, é não aderente ao leito da lesão, e também é de fácil aplicação e remoção(15).

Aos pacientes que relatam dor, a cobertura de espuma não aderente e ibuprofeno é eficaz na redução da dor de pacientes portadores de úlceras venosas, pois à medida que é liberado exsudato na espuma, libera-se $o$ analgésico com ação tópica ${ }^{(2)}$. Outra cobertura relatada foi o curativo com membrana de celulose bacteriana. Mostrou-se redução na área de ferida, não houve infecção ou reações ao produto em nenhum dos grupos. Pacientes do grupo que usou a membrana mostraram diminuição da dor e interrupção mais precoce do uso de analgésicos ${ }^{(19)}$.

Estudo de caso demostrou a eficácia do uso de alginato de cálcio e sódio como resposta rápida a cura da lesão venosa e diminuição da dor. Ressaltando que o resultado esperado depende da disponibilidade de cobertura adequada e ao conhecimento dos profissionais para conduzir o caso(16).

Também existe estudo relacionado ao uso de papaína $2 \%$ e $4 \%$ para estimular cicatrização nos pacientes com úlceras venosas. Este concluiu que, os géis de papaína a $2 \%$ e $4 \%$ foram efetivos na cicatrização de úlceras venosas, apresentando maior efetividade quanto à redução da área das lesões ${ }^{(17)}$.

Vale ressaltar que algumas coberturas não estão disponíveis no SUS e são de alto valor financeiro, não podendo assim ser adquiridas por alguns pacientes.

O enfermeiro deverá no momento da consulta de enfermagem considerar questões como cognitivo do paciente, ajuda familiar na realização do curativo, poder aquisitivo, adesão ao tratamento para indicação da cobertura correta, pois o uso de forma inadequada poderá acarretar problemas como infecções, internações, dor, entre outros.

As plantas medicinais na forma de chá ou diretamente na lesão venosa também foram citadas. Esse cuidado antecede a busca aos serviços de saúde ou ocorre de forma complementar as práticas profissionais. Faz-se importante a enfermagem identificar a influência desse conhecimento popular no cuidado a pessoas com UV(14).

A oxigenoterapia hiperbárica foi citada como terapia adjuvante no manejo da úlcera, estudo mostrou que os pacientes com feridas crônicas realizaram menor número de sessões $(61,1 \%)$ e tiveram suas feridas cicatrizadas ou reduzidas $(62,0 \%)$ quando comparados com aqueles com feridas agudas. Então, a terapia por oxigênio hiperbárico é um tratamento efetivo para pacientes com feridas crônicas ${ }^{(17)}$.

\section{Estudos fenomenológicos e compreensão}

Nesta categoria, foram evidenciados 7 estudos, sendo estes $22 \%$ da amostra. Estudos relevantes, qualitativos, onde dois deles utilizaram a fenomenologia como referencial teórico(14).

Com a realização dos estudos, os autores buscaram compreender o cotidiano do homem e a vivência de cuidado de pessoas com UV em uso da bota de Unna, no qual foram desveladas as categorias:"O incomodo da bota de Unna versus a melhora da ferida", "Dificuldades para o acesso ao cuidado com a Bota de Unna", "Cuidar para cicatrizar e prevenir recidivas" e "Receber mais atenção do profissional de saúde".

Concluiu-se neles que a vivência de cuidado de pessoas em uso da Bota de Unna revelou o incomodo proporcionado por este dispositivo, superado pela melhora da ferida. As questões do universo intersubjetivo dessas pessoas devem ser consideradas na gestão do cuidado da UV.

Outro estudo identificou as experiências construídas pelas pessoas com UV no processo de conviver com esta condição crônica, revelando que a pessoa com UV pode apresentar propensão a desenvolver problemas que colocam em risco a sua saúde física e emocional(20).

Portanto, conhecer as alterações ocorridas no cotidiano de pessoas acometidas com esta patologia, identificarsuas limitações nas atividades cotidianas de lazer e laborais, bem como reconhecer sentimentos e sensações de angústia e sofrimento que interferem em suas relações sociais, podem promover um cuidado de enfermagem mais holístico(19).

Artigo avaliou o bem-estar subjetivo e depressão em pessoas idosas com UV e evidenciou que,indivíduos apreาsentam depressão entre leve a severa e queda na qualidade de vida, os mesmos sentem 7 -se infelizes, e insatisfeitos com a vida ${ }^{(17)}$.

Estudos descreveram o cuidado em saúde realizado pelas pessoas com UV em assistência ambulatorial, sendo que as práticas de cuidado realizadas se referem à alimentação, à ferida e ao repouso.Essas práticas de cuidado devem ser conhecidas pela enfermagem, pois isso possibilitará a troca e aproximação de saberes em busca de um cuidado congruente, além deinvestigar o sentimento de inclusão social de pessoas com UV. Também se faz necessário pelo enfermeiro repensar práticas assistenciais inclusivas e receptivas que transcendam a técnica de curativo e compreendam o ser humano em sua complexidade ${ }^{(20,21)}$.

\section{Estudos metodológicos e de validação}

$\mathrm{Na}$ categoria relacionada a estudos metodológicos, foram achados 7 (22\%) artigos. Dois estudos foram relacionados à elaboração de protocolos assistências, dois foram relacionados a uso de softwares, dois artigos utilizaram escalas de mensuração para tamanho das lesões venosas, e um estudo foi acerca da elaboração de uma cartilha para cuidados a pacientes 
com UV.

Estudo de Dantas realizou validação de conteúdo e validação clínica de um protocolo assistencial para pessoas com UV em serviços de saúde de alta complexidade. O protocolo foi validado no contexto clínico, e sua composição, após os ajustes, foi de 15 categorias e 76 itens ${ }^{(22)}$.

Para compor o protocolo, foram necessários aspectos referentes a diagnóstico, tratamento e prevenção das lesões, avaliação do paciente e lesão, registro/documentação, cuidado com ferida/pele perilesional, indicação de cobertura, uso de antibiótico e tratamento da dor, tratamento cirúrgicol medicamentoso, melhoria do retorno venoso, prevenção de recidiva, encaminhamento dos pacientes, capacitação e referência/contra-referência ${ }^{(14,22)}$.

Outro estudo apresentou um sistema especialista denominado PROTUV-software (protocolo para Tratamento de Úlceras Venosas) para apoiar o processo de decisão dos enfermeiros na terapia tópica das úlceras venosas. A utilização deste recurso viabilizou a educação permanente dos enfermeiros sobre o tratamento de feridas, bem como a inclusão digital destes enfermeiros para o uso do sistema ${ }^{(7)}$.

Eberhardt utilizou dois softwares (AutoCAD $\cap$ e Image Tool) para comparar a mensuração de área de úlceras venosas e concluiu que o uso de ambos os softwares é indicado para a mensuração de úlceras venosas, parecendo ser mais precisos quando utilizados para mensurar feridas com área $>10 \mathrm{~cm}^{2(16)}$.

Pereira e Santo, utilizaram a escala PressureUlcerScale for Healing- PUSH em seus estudos para descreverem a evolução da cicatrização e $\circ$ trata $\neg$ mento realizado em pacientes com úlceras de perna no ambulatório de feridas ${ }^{(17,23)}$.

O referido instrumento facilita a atuação da enfermagem na avaliação e na escolha da cobertura ideal para a promoาção da epitelização da lesão, uma vez que tem por base a avaliação de parâmetros importantes durante o processo dinâmico do cuidar de feridas.

Benevides construiu e validou uma tecnologia educativa (cartilha) para cuidados com UV. A cartilha é constituída de sete tópicos: alimentação, caminhadas e exercícios leves, repouso com a perna elevada, cuidados com o curativo, terapia compressiva, apoio familiar, e manter hábitos saudáveis. 0 piloto revelou que $100 \%$ das pessoas com UV avaliaram o texto como compreensivo e as ilustrações, como adequadas ${ }^{(24)}$.

\section{Diagnósticos, uso do processo de enfermagem e elaboração de consulta de enfermagem}

Nesta categoria de estudos, foram encontrados 3(9\%) de artigos relacionados a esta temática.

Nogueira analisou os diagnósticos de enfermagem em pessoas com úlcera venosa crônica. Nele identificaram-se 16 diagnósticos, sendo que $100 \%$ dos participantes apresentaram: integridade tissular prejudicada, perfusão tissular periférica ineficaz, risco de infecção, mobilidade física prejudicada e autocontrole ineficaz da saúde ${ }^{(25)}$.Estes diagnósticos encontram-se nos domínios Segurança/Proteção, Atividade/ Repouso e Promoção da Saúde. Do ponto de vista da prática clínica estes devem ser focos prioritários na intervenção e avaliação de enfermagem ${ }^{(25)}$.

Ademais, Almeidaidentificou o grau de comprometimento da integridade tissular de pacientes com UV de acordo com a classificação dos resultados de enfermagem. Cinco indicadores apresentaram comprometimento moderado (mediana $=3$ ): dor, perfusão tissular, pigmentação anormal, crescimento cutâneo de pelos e tecido cicatricial. Concluem que a maioria dos indicadores avaliados nos pacientes entrevistados apresentou grau de comprometimento variando de leve a moderado(2).

Estudo internacionaldesenvolveu um modelo simples de consulta de enfermagem baseada em evidências, com pacientes e profissionais, com foco na qualidade de vida. Um modelo de folha A4 frente e verso de fácil utilização foi projetado para concentrar as consultas enfermeiro-paciente nos desafios de qualidade de vida apresentados pelas úlceras venosas crônicas. Os autores concluem que este novo modelo ajudará a garantir que as principais preocupações sejam efetivamente levantadas, exploradas e abordadas durante cada consulta ${ }^{(26)}$.

Pensando nesta perspectiva, a essência da enfermagem é o cuidar e a Sistematização da Assistência de Enfermagem. Notase carência de publicações envolvendo a temática, o que se torna preocupante, visto que, o instrumento metodológico orienta o cuidado profissional de enfermagem e a documentação se faz necessária para o planejamento, execução e avaliação do cuidado, constituindo assim, uma ferramenta fundamental ao trabalho do enfermeiro, tornando-acientífica, sistemática e dinâmica na prestação de cuidados humanizados para a obtenção dos melhores resultados.

\section{Programas de aconselhamento e educação na visita domiciliar}

Nesta categoria encontrou-se apenas 2 (6\%) artigos. Um deles avaliou o impacto da visita domiciliar na capacidade funcional de pacientes adultos e idosos com úlceras venosas. Os participantes do grupo caso apresentaram melhora significativa pós-intervenção, quando comparados aos do grupo controle, evidenciando assim, que as orientações no contexto domiciliar foram benéficas aos integrantes do grupo caso(24,28).

Estudo internacional, analisou o conhecimento dos pacientes sobre a doença venosa crônica, ocorrência de UV e recorrência, auto-cuidado, no início, imediatamente e após, duas e nove semanas após uma intervenção educativa realizada no domicílio dos sujeitos. Os resultados sugerem que a educação do paciente relacionada às úlceras venosas melhora o conhecimento sobre o processo da doença e o autocuidado e reduz a recorrência quando medida às 9 semanas após a intervenção. Além disso, metade dos pacientes que completaram a intervenção educacional permaneceu livre de recorrência quando avaliada em nove semanas ${ }^{(27)}$.

Para tanto, nota-se que, os cuidados de enfermagem aliado à educação e à promoção da saúde, traz excelentes resultados, interação enfermeiro e paciente ealcance de metas como foco de ação para a qualidade de vida.

\section{REFERÊNCIAS}

1. Medeiros ABA, Frazão MCFQ, Sá JD, Lira ALBC, Lopes MVO. Compromiso tisular de pacientes con úlcera venosa según las clasificaciones de los resultados de enfermería. Enferm. glob. [Internet]. 2014 [Acesso em 2018 mar 28]; 13(36): 26-34. Disponível em: http://scielo.isciii.es/scielo.php?script=sci_ arttext\&pid=SI695-6I4I $20 \mid 4000400002$.

2. Almeida SA, Moreira CNO, Salome GM. PressureUlcerScale for Healing no acompanhamento da cicatrização em pacientes idosos com úlcera de perna. Rev. Bras. Cir. Plást. [Internet]. 2014 [Acesso em 2018 mar 28]; 29(I): I20-I27. Disponível em: http:// www.rbcp.org.br/details/I500/pressure-ulcer-scale- 
for-healing-no-acompanhamento-da-cicatrizacao-empacientes-idosos-com-ulcera-de-perna. DOI: http:// www.dx.doi.org/I0.5935/2 I 77-I235.20 I4RBCP0020.

3. Collins MDL, Seraj MDS. Diagnosis and Treatment of Venous Ulcers. AmFamPhysician [Internet]. 2010 [Acesso em 2019 abr 20]; 8I(8): 989-996. Disponível em: https://www.aafp.org/afp/2010/0415/p989.html.

4. Vieira CPB, Araújo TME. Prevalence and factors associated with chronic wounds in older adults in primary care. RevEscEnferm USP [Internet]. 2018 [Acesso em 2019 abr 20]; 52: e034I5. Disponível em: $\quad$ http://www.scielo.br/scielo.php?script=sci_ arttext\&pid=S0080-623420 I 8000 I 0049 I \&lng=pt\&nr m=iso\&tlng=pt. DOI: http://dx.doi.org/ I0.1590/SI 980220X20I705I3034I5.

5. Abbade LPF, Lastória S. Abordagem de pacientes com úlcera da perna de etiologia venosa. $\mathrm{Na}$ Bras Dermatol [Internet]. 2006 [Acesso em 2019 abr 20]; 8I(6): 509-22. Disponível em: http://www.scielo.br/scielo. php?pid=S0365-05962006000600002\&script =sci_ abstract\&tlng=pt. DOI: http://dx.doi.org//0.1590/ S0365-05962006000600002.

6. Tavares APC, Sá SPC, Oliveira BGRB, Sousa AI. Qualidade de vida de idosos com úlceras de perna. Esc Anna Nery [Internet]. 2017 [Acesso em 2019 abr 20]; 21 (4): e20170134. Disponível em: http://www.scielo.br/scielo.php?pid=SI4 |4$8 \mid 452017000400229 \&$ script $=s c i \_$arttext\&tlng=pt. DOI:http://dx.doi.org/l0.1590/2177-9465ean-20l7-0I34.

7. Sellmer D, Carvalho CMG, Carvalho DR, Malucelli A. Sistema especialista para apoiar a decisão na terapia tópica de úlceras venosas. Rev. Gaúcha Enferm. [Internet]. 2013 [Acesso em 2018 mar 29]; 34(2): I54-I62. Disponível em: http://www. scielo.br/scielo.php?script=sci_arttext\&pid=S I 983| 44720|3000200020\&lng=en\&nrm=iso. DOI: http:// dx.doi.org/| 0.1590/SI983-|44720|3000200020.

8. Soares CB, Hoga LAK, Peduzzi M, Sangaleti C, Yonekura T, Silva DRAD. Revisão integrativa: conceitos e métodos utilizados na enfermagem. RevEscEnferm USP [Internet]. 2014 [Acesso em 2019 abr 20]; 48(2): 335-45. Disponível em: http://www.scielo.br/scielo. php?pid=S0080-623420 $4000200335 \&$ script $=$ sci_ arttext\&tlng=pt. DOl:http://dx.doi.org/ I0.1590/S00806234201400002000020 .

9. Galvão, TF, Pansani,TSA, Harrad D. Principais itens para relatar Revisões sistemáticas e Metaanálises: A recomendação PRISMA. Epidemiol. Serv. Saúde [Internet]. 2015 [Acesso em $2018 \mathrm{abr}$ I5]; 24(2): 335-342. Disponível em: http://www. scielo.br/scielo.php?script=sci_arttext\&pid=S2237962220 I5000200335\&lng=en\&nrm=iso. DOI: http:// dx.doi.org/I0.5 I23/SI679-497420I50002000I7.

10. Fuchs SC, Paim BS. Revisão Sistemática de Estudos Observacionais com Metanálise. Rev HCPA [Internet]. 20I0[Acesso em 2019 abr 22]; 30(3): 294-30I. Disponível em: https://seer.ufrgs.br/hcpa/article/ view/I655I.

11. Melnyk BM, Fineout-Overholt E. Making the case for evidence-based practice. In: Melnyk BM, Fineout-Overholt E. Evidence-based practice in nursing \& healthcare. A guide to best practice. Philadelphia: Lippincot Williams \& Wilkins; 2005. p. 3-24. Disponível em: http://www.scielo.br/scielo. php? script=sci_nlinks\&ref=000093\&pid=S0 I 04 | | 6920 | | 000600024000 | | \&lng=pt.

12. Abreu AM, Oliveira BRB, Manarte JJ. Treatment of venous ulcers with an unna boot: a case study. Online braz j nurs [Internet]. 2013 [Acesso em 2018 mar 28]; 12(I): 198-208. Disponível em: http://www.objnursing. uff.br/index.php/nursing/article/view/3845. DOI: https://doi.org// 0.5935//676-4285.20133845.

13. Danski MTR, Liedke DCF, Vayego SA, Pontes L, Lind J, Johann DA. Tecnologia bota de unna na cicatrização da úlcera varicosa.CogitareEnferm [Internet]. 2016 [Acesso em 2019 mar 29]; 21(3): 01-09. Disponível em: https://revistas.ufpr.br/cogitare/article/view/48803. DOI: http://dx.doi.org/I0.5380/ce.v2 Ii3.48803.

14. Robaina ML, Budó MLD, Silva DC, Schimith MD, Durgante VL, Simon BS. Saberes e práticas de pessoas com úlcera venosa em tratamento com bota de unna. RevEnferm UFSM [Internet]. 2016 [Acesso em 2018 mar 28]; 6(3): 37I-38I. Disponível em: https:// periodicos.ufsm.br/reufsm/article/view/21985. DOI: http://dx.doi.org// 0.5902/2 I 7976922 I 985.

15. Calderon MDS, Figueroa CS, Arias JS, Sandoval $\mathrm{AH}$, Torre FO. Combined therapy of Ulmo honey (Eucryphia cordifolia) and ascorbic acid to treat venous ulcers. Rev. Latino-Am. Enfermagem [Internet]. 2015 [Acesso em 2018 mar 29]; 23(2): 259-266. Disponível em:http://www.scielo.br/scielo.php?script=sci_ arttext\&pid=S0 I 04- I | 6920 | $50002000 \mid$ I \&lng=e n\&nrm=iso. DOI: http://dx.doi.org/I0.1590/0104I 169.0020.2550.

16. Eberhardt TD, Lima SBS, Lopes LFD, Borges EL, Weiller TH, Fonseca GGP. Measurement of the area of venous ulcers using two software programs. Rev. LatinoAm. Enfermagem [Internet]. 2016 [Acesso em 2018 mar 26]; 24(I): 0I-06. Disponível em: http://www. scielo.br/scielo.php?script=sci_arttext\&pid=S0 $104-$ I 1692016000100445\&lng=en\&tlng=en. DOI: http:// dx.doi.org//0.1590/I518-8345.1673.2862.

17. Macêdo MML, Souza DAS, Santos JC, Rodrigues RN, Afonso GS, Cortez $\mathrm{AOH}$, et al. Úlcera venosa: seis años de existencia por 92 días de cicatrización. Gerokomos [Internet]. 2016 [Acesso em 2018 mar 28]: 27(3); |3|-|33. Disponível em: http://scielo.isciii. es/scielo.php?script=sci_arttext\&pid=S I I 34928X20160003000 I0\&Ing=es\&nrm=iso.

18. Salomé, GM, Ferreira LM. Impacto do curativo de espuma não aderente com lbuprofeno na vida dos pacientes com úlcera venosa. Rev. Col. Bras. Cir. [Internet]. 2017 [Acesso em 2018 mar 28]; 44(2): II6-I24. Disponível em: http://www.scielo.br/scielo. php?pid=SO I00-699I $20170002001 \mid$ l6\&script=sci_ arttext\&tlng=pt. DOl: http://dx.doi.org/10.1590/010069912017002002 .

19. Cavalcanti LM, Pinto FCM, Oliveira GM, Lima SVC, Aguiar JLA, Lins EM. Eficácia da membrana de celulose bacteriana no tratamento de úlceras venosas de membros inferiores: estudo randomizado e controlado. Rev. Col. Bras. Cir. [Internet]. 2017 [Acesso em 2018 mar 29]; 44(I): 72-80. Disponível em:http://www. 
scielo.br/scielo.php?script=sci_arttext\&pid=SO 100 699|2017000100072\&lng=en\&tlng=en. DOI: http:// dx.doi.org/I0.1590/0100-6991201700101।.

20. Silva DC, Budó MLD, Schimith MD, Durgante VL, Rizzatti SJS, Ressel LB. Itinerário terapêutico de pessoas com úlcera venosa emassistência ambulatorial. Texto Contexto Enferm[Internet]. 2015[Acesso em 2019 abr 22]; 24(3): 722-30.Disponível em:http://www. scielo.br/scielo.php?script=sci_arttext\&pid=S0 $104-$ 070720 I5000300722\&lng=en\&tlng=en. DOI: http:// dx.doi.org/I0.1590/0 I04-070720 I50003200 I4.

21. Joaquim FL, Camacho ACLF, Silva RMCRA, Leite BS, Queiroz RS,Assis CRC. Repercussão da visita domiciliar na capacidade funcional de pacientes com úlceras venosas. RevBrasEnferm [Internet]. 2017 [Acesso em 2019 abr 22]; 70(2):304- I I. Disponível em:http://www. scielo.br/scielo.php?script=sci_arttext\&pid=S003471672017000200287\&lng=en\&tlng=en. DOI: http:// dx.doi.org/ I0.1590/0034-7|67-20 I6-029I.

22. Dantas DV,Dantas RAN, Costa IKF,Torres GV.Protocolo de assistência a pessoas com úlceras venosas: validação de conteúdo. Revista Rene [Internet]. 2013 [Acesso em 2018 mar 29]; I4(3): 588-599. Disponível em: http:// www.periodicos.ufc.br/rene/article/view/3496.

23. Joaquim FL, Silva RMCRA, Garcia-Caro MP, CruzQuintana F, Pereira ER. Impacto das úlceras venosas na qualidade de vida dos pacientes: revisão integrativa. RevBrasEnferm [Internet]. 2018[Acesso em 2019 abr 22]; 7I(4):2I37-46. Disponível em:http://www. scielo.br/scielo.php?script=sci_arttext\&pid=S00347|6720 |800040202 | \&lng=en\&tlng=en.DOI: http:// dx.doi.org/I0.1590/0034-7|67-2017-05।6.

24. Benevides JL, Coutinho JFV, Pascoal LC, Joventino ES, Martins MC, Gubert FA, et al. Development and validation of educational technology for venous ulcer care. Rev. esc. enferm. USP [Internet]. 2016 [Acesso em 2018 mar 29]; 50(2): 309-316. Disponível em: http://www.scielo.br/scielo.php?script=sci_ arttext\&pid=S0080-623420 I 6000200309\&lng=en \&nrm=iso. DOI: http://dx.doi.org/I0.1590/S0080623420160000200018 .

25. Joaquim FL, Camacho ACLF, Sabóia VM, Santos RC, Santos LSF, Nogueira GA. Impacto da visita domiciliar na capacidade funcional de pacientes com úlceras venosas. Rev. Bras. Enferm. [Internet].
2016 [Acesso em 2018 mar 29]; 69(3): 468477. Disponível em: http://www.scielo.br/scielo. php?pid=S0034-7 $6720 \mid 6000300468 \&$ script $=$ sci abstract\&tlng=pt. DOI:http://dx.doi.org//0.1590/00347167.20I6690308i.

26. Green J, Jester R, McKinley R, Pooler A, Mason S, Redsell S.A new quality of life consultation template for patients with venous leg ulceration. Journal of Wound Care [Internet]. 2015 [Acessoem 2018 abr I5]; 24(3): |40-|48. Disponívelem: https://www.ncbi.nlm.nih.gov/ pubmed/25764959. DOI: http://dx.doi.org//0.12968/ jowc.2015.24.3.140.

27. González A. Education Project to Improve Venous Stasis Self-management Knowledge. Journal OfWound, Ostomy And Continence Nursing [Internet]. 2014 [Acessoem 2019 abr I5];4I (6):556-559.Disponível em: https://www.ncbi.nlm.nih.gov/pubmed/25377/05. DOI: http://dx.doi.org// 0.1097/WON.0000000000000088.

28. Nunes HJM, Queirós PJP. Patient with stroke: hospital discharge planning, functionality and quality of life. RevBrasEnferm[Internet]. 2017 [Acesso em 2019 abr I5]; 70(2):433-42.Disponível em:http://www. scielo.br/scielo.php?script=sci_arttext\&pid=S00347|6720 I70002004 I5\&lng=en\&tlng=en. DOI: http:// dx.doi.org/l0.1590/0034-7I67-2016-0166.

29. Araújo RO, Silva DC, Souto RQ, Marconato AMP, Costa IKF, Torres GV. Impacto de úlceras varicosas en la calidad de vida de individuos atendidos en atención primaria.Aquichan[Internet]. 2016 [Acesso em 2019 abr 15]; 16(I):56-66. Disponível em: http:// aquichan.unisabana.edu.co/index.php/aquichan/article/ view/5574/pdf\%20\%28Portugu\%C3\%A9s\%29. DOI: http://dx.doi.org/10.5294/aqui.2016.16.I.7.

30. Asociación Española de Enfermería Vascular y Heridas. Guía de práctica clínica: Consenso sobre úlceras vasculares y pie diabético. Madrid: AEEVH [Internet]. 2017 [Acesso em 2019 abr 15]; 3:I-I40. Disponível em: https://gneaupp-Ifb3.kxcdn.com/wp-content/ uploads/20I 7/06/Guia-de-Practica-Clinica-web.pdf.

Recebido: 2019-07-30 Aceito: $2019-08-25$ 